\title{
SUBJECTIVE WELL-BEING, SOCIETAL CONDITION AND SOCIAL POLICY - THE CASE STUDY OF A RICH CHINESE SOCIETY
}

(Accepted 2 August 2005)

\begin{abstract}
The article looks at whether or not social policy and other societalcondition variables contribute to the subjective well-being of life satisfaction. It firstly argues that social policy needs to pay more attention to the study of subjective well-being. Then, it reviews the literature and finds that people in rich societies generally have higher levels of life satisfaction. But the findings of a social survey on the level of and variance in life satisfaction in a rich Chinese society reveal the contrary. The empirical data reflects a life satisfaction pattern along strong income and class lines. It also confirms that social policy and other societal-condition variables have different degrees of impact on life satisfaction. At last, implications of the findings for social policy are discussed.
\end{abstract}

KEY WORDS: attitude study, life satisfaction, social policy, subjective well-being, welfare indicators

\section{INTRODUCTION}

Life satisfaction, a global cognitive judgment of one's life, is one of the frequently used indicators to measure subjective well-being that reflects how individuals appreciate their personal lives. Satisfaction with life is not only of people's command over resources, but also the efforts they put into securing their well-being. Hence, satisfaction with one's life captures the active side of human beings as moral agents, who makes choices and efforts, not as passive recipient of their surroundings. Happiness is another subjective well-being indicator, but on the affective side, empirically correlated with life satisfaction but conceptually different - it is about people's emotional state and is sensitive to sudden changes in mood. 
According to Fahey and Smyth (2004), the measures of life satisfaction and happiness and other related dimensions of subjective well-being have gained only limited recognition as instruments for the social-scientific analysis of human welfare, but are prominent in the field of psychology and some sub-fields in sociology. It is because subjective well-being measures are reported to be invariant to objective, societal conditions such as economic change. For example, Diener and Suh's (1997) 1946-1990 trend study of subjective wellbeing in France, Japan, and the United States does not identify any significant change despite tremendous economic growth over the same period. Oswald (1997) finds that there was virtually no increase in subjective well-being in nine European nations during a period of rapid economic growth.

Prominent scholars in the field of psychology find that subjective well-being and personality traits emerge early in life, are fairly stable over time, and have a moderate to strong genetic characteristic (Diener and Lucas, 1999; Diener et al., 1999). This may imply that investigating the relations between subjective well-being and societal conditions such as average national income or wealth is not very practical or worthwhile.

Despite skepticism towards the relationship between income or wealth and subjective well-being, when researchers undertake comparative studies which include poorer countries, the cross-country data often shows much stronger correlations between subjective wellbeing measures and a nation's average income. People in wealthier countries are found, on average, to be more satisfied with their lives than people in poorer countries. Not only are the correlations positive, they are also strong - for example, 0.59 in Diener et al. (1995); 0.51 and 0.59 in Veenhoven (1991, 1995); and 0.64 in Schyns (1998). Even cross-level correlation finds that poor people in poor countries are less satisfied than poor people living in affluent countries. Hence, the insignificant effect of objective, societal condition on subjective well-being may be due to the earlier exclusive within-country or crosscountry study of subjective well-being in a number of highly developed countries (Fahey and Smyth, 2004, p. 7).

Following this lead, this article looks at whether social policy, alongside other societal-condition variables, contributes to the subjective well-being of life satisfaction. Social policy programs such as education and social security are social infrastructure, which is 
supposed to enhance the life quality of a society. The study on the relationship between subjective well-being and social policy should deserve more attention in academic writing than it is now. It is the aim of this article to explicitly look at this relationship. There are a few reasons that social policy needs to pay more attention to subjective well-being measures.

Firstly, social policy is never limited to the pursuit of merely material goals (Veenhoven, 2002); the ideas of trust, social cohesion, and sense of security have always found their places in social policy. These non-material goals are mental matters, like happiness and life satisfaction, which reflect people's affection, mood, or self-evaluation, and their relations with their environment. In other words, subjective well-being measures are not foreign to social policy.

Secondly, subjective well-being is a valuable outcome measure of societal conditions which meet people's needs and capacities (Noll, 2002 , p. 12). It is not to be assumed that social policy would have a positive impact on society. For example, contrary to expectations that life should be better with a high level of social security, a crosscountry study of 42 nations finds that social security expenditures did not have any significant impact on well-being indicators of the unemployed (Ouweneel, 2002). Hence, it would be beneficial for social policy to demonstrate its impact for the well-being of society, especially in a fiscally constrained environment.

Thirdly, on a theoretical vantage point, the traditional focus of social policy on income redistribution may overlook the point that income, as some argue, does not produce an extra effect on life satisfaction; if basic needs have been fulfilled, income may have a diminishing marginal utility (Veenhoven, 1991; Schyns, 1998). This has important policy implications: more redistribution may produce similar or less well-being. So, subjective well-being of life satisfaction may have the policy goal or measure that has the potential of constraining the unending demand for social welfare. In sum, the linking of social policy to the study of subjective well-being of life satisfaction should have significant policy implications, especially in the present era of fiscal constraints.

Next the article will look at the literature about the relations between subjective well-being and societal condition; then, it follows by an examination of the findings of a social survey in Hong Kong, a Chinese society, to see whether or not - and to what degree - societal 
conditions affect subjective well-being in the case of life satisfaction. At last, the article discusses the implications of the findings for social policy.

\section{Subjective well-being and societal condition}

The recent ascendance of interest on subjective well-being and its relation to objective, societal conditions, especially in the context of cross-country studies, centers on findings that suggest that rich countries may not necessarily have higher subjective well-being than poor countries. The 1999-2000 World Values Survey finding is a case in point. In its combined score of happiness and life satisfaction, the people of Puerto Rico registered the greatest sense of well-being, while the American people only ranked 15th. In this light, one may wonder whether money can buy happiness or satisfaction with life and rethink the value of the prevalent predominantly material yardsticks such as income, wealth, and growth rates, which are used to measure individual welfare and national development.

However, overall, income, an important means for meeting the demand of livelihood, does bring about higher subjective well-being. For example, 19 of the top 25 countries in the league table of the 1999-2000 World Values Survey are high-income countries. ${ }^{1}$ It so happens that two medium-income countries without admirable economic achievements - Puerto Rico and Mexico $^{2}$ - are ranked first and second. In general, the literature points to the positive relationship between rich countries and higher subjective well-being in crosscountry studies.

There are some elaborative findings in the literature in this regard and also with reference to their underlying causes. For instance, in a survey of 11 published studies on cross-sectional correlations within nations and cities between income and subjective well-being, Diener and Biswas-Diener (2002, pp. 122-123) find that the relation is strongest in the very poor sample in Calcutta (correlation: 0.45 ) and in an Indian village (correlation: 0.35 ), whereas the others are comparatively low (e.g., correlation ranged from 0.06 to 0.15 in West Germany; 0.13 in one sample in the United States). Christoph and Noll's (2003) study of life satisfaction in the European Union finds that life satisfaction levels are usually higher in wealthier countries and lower in countries in the south that are also characterized by a 
higher level of income inequality. On the basis of a 25 -year, eightnation data-base, Hargerty (1999) also finds that absolute level of GDP per capita has the largest effect on life satisfaction. Fahey and Smyth (2004) identify, from a 33 European nation data-base, that population in the richest parts of Europe have higher and relatively equal life satisfaction while those in the poorer parts of Europe have lower and unequal life satisfaction.

The above findings point to notion that people in rich countries generally have higher levels of subjective well-being. However, one would wonder whether that may be a factor not of a country's income or wealth, but of its democratic institution and social equality (Diener et al., 1999). So, democracy and social equality may be two alternative explanations for higher life satisfaction.

From a theoretical vantage point, the complicated relation between subjective well-being and societal condition is intrinsic. It is because, by nature, subjective well-being is about people's self-evaluation of their lives or feelings pertaining to their emotional state. In other words, their cognitive-evaluation or affection is not necessarily or entirely tied to material condition. The negative relation between materialism and life satisfaction is a case in question. For instance, Sirgy (1998, p. 230) argues that materialists tend to experience greater life dissatisfaction because they often have a higher expectation of their own standard of living goals than non-materialists. Empirical evidence also shows that materialistic goals and values are very unfavorable to high subjective well-being (Richins and Dawson, 1992; Kasser and Ryan, 1993; Diener and Biswas-Diener, 2002). For instance, Diener and Biswas-Diener (2002, pp. 142-143), in their study of international college students in the United States, find that students placing a high premium on money had an inverse relation with life satisfaction in contrast with students who valued love.

Having said that, it is not to say that income or wealth does not matter. Generally speaking, other things being equal, material conditions such as income and wealth are conducive to higher subjective well-being insofar as it helps people to meet their basic needs. But beyond that, there may be a diminishing marginal utility (Maslow, 1970, p. 100) or it may become flattened (Fahey and Smyth, 2004, p. 23), once basic needs are fulfilled. Apparently, people in rich countries are in an advantageous position in terms of meeting basic needs. It is because rich countries can provide high standards of 
public goods - community facilities, transport services, schools, hospitals, social security, etc; that even the poor can gain considerable benefits.

In the cases of Puerto Rico and Mexico, their comparatively poor national income levels and medium income levels should be sufficient enough to allow the fulfillment of basic needs. On this basis, there may be moderating variables, such as culture (Diener and Diener, 1995; Diener and Biswah-Diener, 2002) and socialization (Inglehart, 2000) that work in their favor more than in the case of the richer countries. According to Diener and Biswah-Diener (2002, p. 151), the cultural approach accounts for the reason why even most relatively poor individuals score high on subjective well-being, because they are involved in, say, productive activities which are respected in their culture. On a national level, if a culture values non-material goals, seemingly in the cases of Puerto Rico and Mexico, it may attain high subjective well-being regardless of a relative lack of material wealth. Nevertheless, researches also identify a positive correlation with individualistic countries and a negative correlation with collectivistic countries because of the different effects of people's socialization into their culture (Diener and Diener, 1995; Diener, et al., 1995). Whilst Inglehart (2000, p. 220) hypothesizes that the relationship between socio-economic conditions and value priorities is not one of immediate adjustments; a substantial time lag is involved for one's basic values to reflect the conditions that prevailed during one's pre-adult years. Putting them all together, culture and environment, both macro-level societal condition as contrasted with genetic, personality factors, may moderate people's perception of their life goals and fulfillment.

In sum, there are two explanations for making sense of the relation between subjective well-being and material or societal condition, particularly income and wealth. Firstly, it is absolute income or wealth that matters. Income and wealth are means for individual and household consumption for basic necessities, which are also related to a society's capacity to provide public goods for fulfilling basic needs. They are especially evident for subjective well-being before a basic need threshold is reached. Secondly, it is what researchers called adaptive expectations (Hagerty and Veenhoven, 2003). People are satisfied with their lives because they engage in activities that are respected in their culture. In other words, we need to be context 
specific in the study of the relation between subjective well-being and societal condition.

\section{The case study of a Chinese society}

What follows in this article is a look at whether or not, and how far, social policy, as a part of the objective, societal condition, affects life satisfaction, from the findings of a social survey of the Chinese in Hong Kong. In other words, what we use in this study is not objective societal condition, but its proxy - subjective perceptions. Subjective indicators from social surveys have the advantage of conveying people's overall judgment, which is hardly represented by objective indicators (Veenhoven, 2002). For instance, indicators of space, light, community facilities, and sanitation can quantify living condition, but it is necessary to add the subjective indicators such as comfort and community relationships from the perspectives of those who have the living experiences into the overall living quality. The survey findings here also enable us to apply regression analysis for having quantifiable findings of whether or not and how far different societalcondition variables affect life satisfaction.

The survey, which applied a stratified random sampling procedure, was undertaken between December 2003 and March 2004. At the end of the survey, a sample of 1040 Hong Kong Chinese adult respondents aged 18 and above was obtained. In general, the respondent sample was quite representative of the general population in terms of a few key comparable demographic and socioeconomic indicators such as gender, age, education, household income, and occupation (Table I). ${ }^{3}$ In addition, Table I reports a sample of individuals who predominantly perceived themselves in the category of lower and low-middle class status, $67.6 \%$, while only $32.4 \%$ regarded themselves as middle, upper-middle, and upper class. Moreover, a little bit more than two-fifths of them had the experience of receiving means-tested social services and benefits - they were referred to two social services, public assistance and public rental housing. We also include respondents with non-negative equity properties, home owners who had the liberty from the sharp downturn of the post-1997 property market which resulted in, at its peak of 106,000 , negative equity loans. ${ }^{4}$ It is assumed that home ownership should have a positive relationship 


\section{TABLE I}

Demographic profile of respondents as compared with the general population in Hong Kong (\%)

\begin{tabular}{|c|c|c|}
\hline & Sample & Population (2003) \\
\hline \multicolumn{3}{|l|}{ Gender } \\
\hline Male & 47.2 & 48.4 \\
\hline Female & 52.8 & 51.6 \\
\hline$(N)$ & $(1040)$ & \\
\hline \multicolumn{3}{|l|}{ Age } \\
\hline $18-30$ & 19.1 & 22.4 \\
\hline $31-59$ & 56.4 & 58.8 \\
\hline 60 and above & 24.5 & 18.8 \\
\hline$(N)$ & $(1039)$ & \\
\hline \multicolumn{3}{|l|}{ Marriage } \\
\hline Married & 66.7 & 59.9 \\
\hline Single and others & 33.3 & 40.1 \\
\hline$(N)$ & $(1040)$ & \\
\hline \multicolumn{3}{|l|}{ Education attainment } \\
\hline Primary & 30.6 & 27.3 \\
\hline Secondary & 51.9 & 51.5 \\
\hline Tertiary & 17.5 & 21.2 \\
\hline$(N)$ & $(1036)$ & \\
\hline \multicolumn{3}{|l|}{ Household income $(\mathrm{HK} \$)^{\mathrm{a}}$} \\
\hline Low (below 10,000) & 29.9 & 30.7 \\
\hline Middle $(10,000-29,999)$ & 48.0 & 45.3 \\
\hline High (30,000 or above) & 22.1 & 24.0 \\
\hline$(N)$ & $(854)$ & \\
\hline \multicolumn{3}{|l|}{ Occupation } \\
\hline Skilled and non-skilled workers & 33.8 & 35.5 \\
\hline Service and sales workers & 34.4 & 31.6 \\
\hline $\begin{array}{l}\text { Administrators/professionals/ } \\
\text { associated professionals }\end{array}$ & 31.8 & 32.9 \\
\hline$(N)$ & $(550)$ & 100.0 \\
\hline \multicolumn{3}{|l|}{ Self-perceived class status } \\
\hline Lower class & 31.5 & \\
\hline Lower-middle class & 36.1 & \\
\hline Middle, upper-middle, upper class & 32.4 & \\
\hline$(N)$ & $(987)$ & \\
\hline \multicolumn{3}{|l|}{ Welfare user $^{\mathrm{b}}$} \\
\hline Means-tested welfare users & 42.3 & \\
\hline Others & 57.7 & \\
\hline$(N)$ & $(1039)$ & \\
\hline
\end{tabular}


TABLE I

Continued

\begin{tabular}{lll}
\hline & Sample & Population (2003) \\
\hline Home ownership & \\
Non-negative asset property & 35.2 \\
Others (negative asset property, rent a flat, etc.) & 64.8 \\
$(N)$ & $(1035)$ & \\
\hline
\end{tabular}

Notes: The figures of the general population were obtained from the Government's Census and Statistics Department in early 2004.

${ }^{\mathrm{a} O f f i c i a l ~ e x c h a n g e ~ r a t e ~}-\mathrm{HK} \$ 7.8=\mathrm{US} \$ 1.0$.

${ }^{\mathrm{b}}$ Means tested welfare users refers two groups of respondents who self-reported that they were: (1) lived in Public Rental Housing; (2) were public assistance recipients respondents or their family members who currently or had received public assistance in the five years preceding the interview.

with life satisfaction on the condition that the property is not a liability. About $35 \%$ of the respondents were home owners with positive property value.

We need to have a brief on the context of Hong Kong in terms of societal condition and life satisfaction. Hong Kong, with its 6.8 million people, is a Special Administrative Region (SAR) of the People's Republic of China. ${ }^{5}$ Despite the fact that Hong Kong does not have a western-style democracy; it enjoys great autonomy in selfadministration under the principle of "One County-Two Systems" since its handover from the British to the Chinese sovereignty in 1997, meaning that the central government in Beijing of Socialist China should not, in principle, intervene into the internal affairs of Hong Kong. According to the Basic Law, Hong Kong's mini-constitution, greater democracy will be developed. So, at least constitutionally and in principle, Hong Kong is moving towards more democracy, compared to its pre-1997 colonial era.

On the economic side, Hong Kong is a society where economic and material pursuits triumph. For instance, it has been voted by a US conservative think tank, the Heritage Foundation, to be the freest economy in the world for ten consecutive years. Hong Kong is also an international financial center, it has the second largest stock market in Asia. No doubt in such a laissez-faire economy that commodifying labor market conditions - for example, lack of unemployment insurance and minimum wage, and a personal savings 
retirement scheme instead of a redistributive state pension - prevail. Perhaps all these market-dominated features led to Hong Kong's enormous economic achievements. For example, Hong Kong's GDP per capita in 2003 was US\$23,273; that is a level, in any sense, comparable with many Western rich countries. But Hong Kong's income inequality is phenomenal - in 2001, it recorded a gini index of 52.5, one that surpasses any of the 33 European countries in Fahey and Smyth's study. ${ }^{6}$ When we undertook our survey, it did not have the level of life satisfaction that we should expect it according to its level of average income; its variance in life satisfaction was also wide (see below).

In terms of public goods, Hong Kong has good physical infrastructure. In general, its public transport system and utilities are efficient, reliable, and accessible to all of its citizens. It has one of the largest container ports in the world, and is boasted as the gate-way to China. Its international airport was rated the best worldwide in $2005 .^{7}$ On the social infrastructure side, Hong Kong's welfare system is often characterized as selective or residual (McLaughlin, 1993; Holliday and Wilding, 2003; Ramesh, 2004). In fact, it is more of a neo-liberal welfare state (Walker and Wong, 1996), one that goes beyond residual levels, if social services are regarded as promoting economic development (Chau and $\mathrm{Yu}, 2005$; Wong and Wong, 2005). In one authority's words, it is a productivist (Holliday, 2000). In some sense, social services in this SAR of China are quite impressive it has a universal health care system, which is inherited from the colonial era, and it provides nine-year free basic education to all, even beyond that level, there are heavy state subsidies. Despite the fact that public housing is means-tested, but nearly half of the population lives in different types of public housing, rental or government sold units. At the end, all citizens in this Chinese society are guaranteed basic social protection of income, education, housing, and health care. The conception of the selective nature of Hong Kong's welfare state may be derived from its limited social expenditures. In 2000, social spending was $13.7 \%$ of its GDP (Walker and Wong, 2005: Table 1.2); whereas the general level was around one-fifth to onefourth of GDP in OECD countries.

Perhaps it is the changes in the larger societal context that matter, as Hong Kong, at the time of the survey, had experienced severe difficulties at economic, social, and political fronts. It had negative 
growth rates five out of six years (1998-203), the worst being minus $5.1 \%$ in 1998, while in the seven years before the SAR was founded, in 1997, it had very robust records - the highest being 14.1 in 1992 and the lowest being $6.1 \%$ in 1995; while GDP per capita had also dropped from its peak in 1997 from US\$26,563 to 23,273 in $2003 .{ }^{8}$ Unemployment was high; it once peaked at a rate a little bit above $8 \%$ and settled at $7.1-7.2 \%$ when this survey was conducted, definitely not high rates when compared with those in European countries, but extremely high considering the fact that Hong Kong's pre-1997 working population was basically fully employed - unemployment rates were generally lower than $3 \%$.

It was not the worst. In the spring of 2003, the outbreak of Severe Acute Respiratory Syndrome resulted in a loss of nearly 300 lives; this was followed by the political dispute over a national security bill, which was widely regarded by the Hong Kong Chinese as a threat to personal freedom. On 1st July 2003, the date when Hong Kong citizens celebrate the anniversary of the SAR Hong Kong, half a million of them, from all walks of life, took to the street to protest the national security bill, which was, in their view, the result of an incompetent, irresponsive government. The mounting political pressures finally ended with the postponement of the bill and the resignation of the Secretary of Security Bureau, who was responsible for the bill, from the SAR Hong Kong Government. In general, 2003 was the worst year for the Hong Kong Chinese after the founding of this SAR of China in 1997.

The above brief reference to Hong Kong's social, economic, and political conditions during the time that the survey was undertaken provides us a glimpse of the larger societal contexts which might affect subjective well-being. It seems that, perhaps it is not absolute income, but income relative to the past and the changing societal condition that matter. In this light, Hong Kong's case study may allow us to examine whether or not and how far subjective indicators of social policy and other societal conditions affect life satisfaction.

\section{The findings}

We first looked at the perceptions of life satisfaction in Hong Kong. We adopted the Satisfaction with Life Scale developed by Diener et al. (1985), which has been used in some local studies (Cheung, 
1998; Chan et al., 2003). A 5-point scale, which ranged from strongly disagree to strongly agree, was used to measure the responses to the five items of the scale. We found that only the item "I am satisfied with my life" received more than half of the respondents' endorsement (56.6\%, Table I, item 3). Among the rest, the next most common response, which was agreed upon by one-third of respondents, to different extents, was "In most ways my life is close to my ideal" (Table I, item 1); the least satisfied is the item that "The conditions of my life are excellent," with one-fifth of respondents in agreement, to different extents (Table I, item 2). Overall, the response pattern can hardly be interpreted to suggest that the Chinese people, despite their high average income levels, were satisfied with their lives.

On an aggregate 10-point scale, which is seemingly more differential, a 5.51 mean was scored (Table I, $\alpha=0.738$ ), which literally means that the Hong Kong Chinese were neither satisfied nor dissatisfied with their lives in general - a neutral stand. Variance was wide, with two-thirds scoring below the median (i.e., 5.5 on a 10 -point scale). The mean score is consistent with those identified in previous local studies. For instance, the Quality of Life studies by the Chinese University of Hong Kong, using the same Satisfaction with Life scale, identifies the mean of 5.3, 5.55, and 5.77, respectively, in 2002, 2003, and 2004. ${ }^{9}$

According to Diener and Diener (1996, p. 184), most people have subjective well-being above the average; they hypothesize a positive baseline for affects in human beings. For instance, in the seminal paper which reports the Satisfaction with Life scale, Diener, et al. (1985) find that the sample of undergraduates scored a mean of 23.5 on a scale from 5 to 35 , the median being 20 ; while the elderly sample had a mean of 25.8. They all showed positive satisfaction with life. In other measures of subjective well-being, Diener et al. (1997) find that $85 \%$ of Americans have a positive level of subjective well-being. On this basis, it seems that our respondents, as a group, were neutral with their regards to their perception of life; and worst of all, only $34.5 \%$ of the respondents had positive subjective well-being of life satisfaction (Table II, the percentage above the median of 5.5). This also suggests that the Hong Kong sample had a wide variance, with a heavy concentration on the dissatisfaction side of the 10-point scale: $65.5 \%$, while only $2.2 \%$ of the respondents were on the top three deciles (Table II). 
TABLE II

Levels and variance in life satisfaction in Hong Kong, 2003-2004

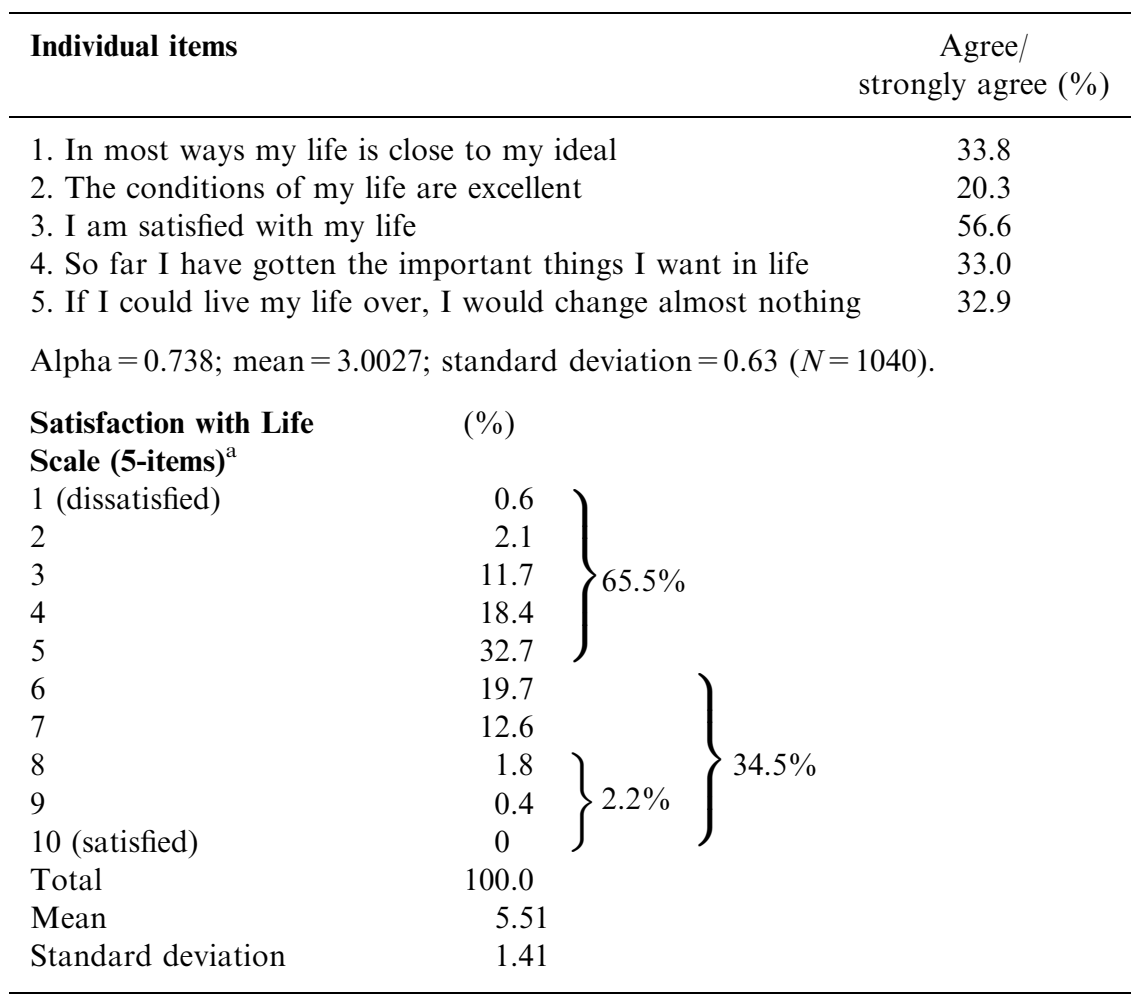

${ }^{\mathrm{a}}$ The percentage present in the table was converted from 5-point scale to 10-point by the following formula: $1+(X-1) \frac{10-1}{5-1}$.

Evidently, despite a comparatively high national average income level, Hong Kong does not have the level and variance of life satisfaction one might expect. In other words, absolute national income is not a sufficient factor, at least in the case of Hong Kong, for having high subjective well-being such as life satisfaction.

Next we will consider whether or not and how far the perceptions of some societal conditions (i.e., social, economic, and political factors) affect life satisfaction. The data are generated from the same database as those we had on life satisfaction above. There are six variables for perceived societal condition; they are as follows: satisfaction with social and economic conditions, perception of adequacy of social mobility, perception of adequacy of government-provided 
social services, perception of severity of social problems, perception of social problem causation, and satisfaction with governance. Apparently, they are relevant to life satisfaction. For example, better social and economic conditions provide a livable environment, which should enhance life appreciation; social mobility allows more choices for diverse life chances; and good governance is important for collective responses for unwanted social, economic, and political problems. In addition, personal characteristic variables, as those mentioned above, are also included in the analysis to see how far they offer alternative explanations for life satisfaction.

Table III provides a glimpse of the respondents' perceptions of a few selected major perceived societal conditions in Hong Kong at the time of the survey. The respondent group was generally pessimistic. Only one-fourth and one-tenth of the respondents were satisfied, to different extents, with Hong Kong's social and economic conditions, respectively (Table III, Statement 1). Only one-fourth of the respondents thought that social mobility in Hong Kong were adequate or very adequate (Table III, Statement 2). Even the provisions of social services, the output of social policy, were not generally regarded as adequate at different extents - ranging from the mid-40s in housing, public assistance, and low-40s for health, to about 30s for elder care, retraining, and job creation (Table III, Statement 3). In terms of the perception of social problems, the three major social problems received poor ratings - nearly four-fifths, two-thirds, and three quarters of the respondents thought that unemployment, poverty, and income gap, respectively, were serious or very serious (Table III, Statement 4). Nevertheless, public security at two levels in general and at the local community where the respondents lived were regarded as safe; only $1 / 8$ th and $1 / 20$ th of the respondents thought that public security and public security, respectively, in their living community, were a serious problem (Table III, Statement 4). Moreover, social problems were perceived by just a little bit more than half of the respondents to be a matter of social causation (Table III, Statement 5). The last is a political dimension - the governance in Hong Kong. About one-eighth of the respondents was satisfied, to different extents, on all three respective items on governance in Hong Kong - the performance of the Chief Executive of the SAR Government, confidence in the future of Hong Kong led by the Chief Executive of the SAR Government, and the overall perfor- 
TABLE III

Respondents' perceptions of societal conditions in Hong Kong, 2003-2004 (\%)

1. Satisfaction with social and economic conditions

Social condition

Economic condition

2. Perception of adequacy

for social mobility

Social mobility opportunity

3. Perception of adequacy of

government-provided social services

Elderly

Housing

Education

Health

Public assistance

Re-training/job creation

4. Perception of the severity

of social problem

Gap between rich and poor

Poverty

Unemployment

Public security

Public security in living community

4. Perception of social problem

Socially caused

Others

5. Satisfaction with governance

Satisfied with the performance of the Chief

Executive of the SAR Government

Confidence in the future of Hong Kong

SAR led by the Chief Executive of the

SAR Hong Kong Government

Satisfied with the overall performance of

SAR Hong Kong Government
Satisfied/very satisfied

25.7

10.0

Adequate/very adequate

21.8

Adequate/very adequate

30.8

46.2

40.4

44.4

45.7

27.7

Serious/very serious

74.6

61.8

78.9

12.6

4.8

53.8

46.2

12.0

$(N=1040)$

mance of the SAR Government (Table III, Statement 6). Seemingly, the earlier political dispute over the national security bill still seemed to come into consideration.

Despite our earlier generally positive evaluation of Hong Kong's overall societal conditions - high average income levels, somewhat modest to excellent physical and social infrastructure, and new selfautonomous status as contrasted with the earlier colonial rule, albeit against the background of the worst year (i.e., 2003) since the handover 
in 1997 - the findings give us a cold reminder that evaluation, in general, is in the eye of the beholder. This subjective dimension fits well with the underlying rationale of subjective well-being - the active side of human agency which may be relatively autonomous from objective, societal condition. It also reveals the complications of human society - not only societal condition is objectively counted, but also subjectively interpreted by people in relation to circumstantial factors.

Now, we turn to the findings of regression analysis in Table IV, which examines whether or not and how far social policy and other societal conditions, in terms of the respondents' perceptions, together with personal characteristics, affect life satisfaction. The coding of all these explanatory variables is presented in Box 1. Satisfaction with social and economic conditions had the strongest positive impact ( $\beta=0.119, p<0.01$ ), followed by perception of adequacy of government-provided social services $(\beta=0.112, p<0.001)$. Perception of the severity of social problems $(\beta=-0.097, p<0.01)$ and perception of adequacy of social mobility $(\beta=-0.076)$ had negative impacts on life satisfaction. The other two societal-condition variables, perception of social problems as socially caused and satisfaction with governance did not have any significant effect on life satisfaction. All these societal-condition variables explained $8.6 \%$ of the variance.

Amongst all the personal characteristics, age, self-perceived class status, and household income had the most significant effect on life satisfaction. Age produced a positive and significant correlation with life satisfaction $(\beta=0.217, p<0.001)$, while the perception of class status $(\beta=0.204, \quad p<0.001)$ and household income $(\beta=0.149$, $p<0.01)$ all had significant positive impacts on life satisfaction. Other personal characteristics - gender, marital status, education levels, means-tested welfare use, and home ownership (the effect of other variables being controlled) did not have any significant relationship with life satisfaction. All these personal characteristic variables explained $14.1 \%$ of the variance. In total, these two sets of variables, as a model, explained $22.7 \%$ of the variance.

\section{CONCLUSION}

Contrary to the literature cited above, a rich society like Hong Kong does not have a high level of, and a narrow variance with, life 
TABLE IV

Standard regression coefficients for predicting life satisfaction

\begin{tabular}{|c|c|c|}
\hline & & $N=771$ \\
\hline$R^{2}$ & $0.141 * * *$ & $0.227 * * *$ \\
\hline$R^{2}$ change & & $0.086 * * *$ \\
\hline Constant & 0.555 & 0.885 \\
\hline \multicolumn{3}{|l|}{ Perceived societal conditions } \\
\hline & & $0.119 * *$ \\
\hline $\begin{array}{l}\text { conditions (low to high) } \\
\text { Perception of social mobility }\end{array}$ & & \\
\hline Inadequate & & $-0.076^{*}$ \\
\hline Adequate & & - \\
\hline $\begin{array}{l}\text { Perception of adequacy of government-provided } \\
\text { social services (low to high) }\end{array}$ & & $0.112 * *$ \\
\hline $\begin{array}{l}\text { Perception of severity of social problems } \\
\text { (low to high) }\end{array}$ & & $-0.096^{*}$ \\
\hline \multicolumn{3}{|l|}{ Perception of social problem causation } \\
\hline Social reason & & -0.046 \\
\hline Individual reason & & - \\
\hline Satisfaction with governance (low to high) & & 0.040 \\
\hline \multicolumn{3}{|l|}{ Personal characteristics } \\
\hline \multicolumn{3}{|l|}{ Gender } \\
\hline Female & 0.030 & 0.047 \\
\hline Male & - & - \\
\hline Age (young to old) & $0.255^{* * *}$ & $0.217 * * *$ \\
\hline \multicolumn{3}{|l|}{ Marriage } \\
\hline Married & -0.003 & 0.001 \\
\hline Unmarried & - & - \\
\hline Education (below primary to tertiary or above) & -0.056 & -0.055 \\
\hline Household income (HK\$) (low to high) & $0.148 * *$ & $0.149 * *$ \\
\hline Self-perceived class status (lower to upper class) & $0.260 * * *$ & $0.204 * * *$ \\
\hline \multicolumn{3}{|l|}{ Occupation } \\
\hline Skilled and non-skilled workers & -0.036 & -0.030 \\
\hline Service and sales workers & 0.025 & 0.034 \\
\hline $\begin{array}{l}\text { Others (professional, not in } \\
\text { employment sector, etc) }\end{array}$ & - & - \\
\hline Mean-tested welfare users & 0.023 & 0.000 \\
\hline \multicolumn{3}{|l|}{ Home ownership } \\
\hline Non-negative asset property & $0.087^{*}$ & 0.052 \\
\hline $\begin{array}{l}\text { Others (negative asset property and } \\
\text { rental tenants) }\end{array}$ & - & - \\
\hline
\end{tabular}

$* p<0.05 ; * * p<0.01 ; * * * p<0.001$.

satisfaction as should be expected. The opposite is true. Hong Kong has significant variations in life satisfaction along income and class lines, in terms of cross-level household income and self-perceived 
Box 1: Explanatory variables

\section{Personal Characteristics}

Sex: Female-male

Age: Young to old

Marriage: Married - unmarried

Education: Primary or below - tertiary or above

Household Income: Gross monthly household income, low to high

Self-Perceived Class Status: Lower to upper class

Means-Tested Welfare Users: Public housing tenants and/or

social assistance beneficiaries, users-nonusers

Home Ownership: Non-negative asset property - negative asset

property and rental tenants

\section{Perceived societal conditions}

Satisfied With Social and Economic Conditions (Likert-scale, $\alpha=0.6534$, $m=-0.6453, \mathrm{sd}=1.3783$, low to high): To what extent respondents satisfied with the social and economic condition in HKSAR.

Perception of Social Mobility (Dummy, inadequate - adequate): Opinion on adequacy of the opportunities for upward social movement.

Perception of Adequacy of Government-Provided Social Service (Likert-scale, $\alpha=0.7284, m=0.8037$, sd $=3.6293$, low to high):

Respondents' assessments on adequacy of government provided social service/welfare in areas of (a) elderly; (b) public housing;

(c) education; (d) medical services; (e) CSSA and (f) re-training/job creation services.

Perception of Severity of Social Problems (Likert-scale, $\alpha=0.6624$, $m=1.5824$, sd $=2.5886$, low to high): Respondents' evaluation on the serious of social problem of: (a) gap between rich and poor;

(b) poverty; (c) unemployment; (d) public security; and (e) public security in living community.

Perception of Social Problem Causation (Dummy, social-individual/other reasons): Respondents' opinion on cause of poverty.

Satisfaction with Governance (Likert-scale, $\alpha=0.8784, m=-1.5437$, $\mathrm{sd}=2.3835$, low to high) To what extent respondents (a) satisfied with the Chief Executive's performance; (b) confidence to the future of HKSAR led by the Chief Executive; and (c) satisfied with the overall performance of HKSAR government.

class status. Absolute average income does not bring about a high level of subjective well-being of life satisfaction. A high level of income inequality asserts a strong impact on the variance in life satisfaction amongst the people of Hong Kong. The transition from colonial rule to high-level self-autonomous status, implying more 
democracy at least constitutionally speaking, does not bring higher level of life satisfaction to this SAR of China.

This case study confirms that social policy per se, perceived government-provided social services as its proxy, had a positive, albeit weak, impact on life satisfaction. Despite the selective, neo-liberal nature of its welfare system, welfare use in this Chinese society did not have any significant impact on life satisfaction. It was also found that not all perceived societal factors matter, or matter equally satisfaction with social and economic conditions, perception of social mobility, and perception of severity of social problems had different extents of impact, but not the knowledge of social problem's causation and satisfaction with governance. Evidently, the economic downturn Hong Kong had experienced when the survey was conducted has a negative impact on life satisfaction. These empirical findings reveal the complexity intrinsic in the relationship between societal condition and subjective well-being. The finding on governance is a case in question. Despite enormous political disputes over the national security bill in 2003, this was a non-factor to life satisfaction. Perhaps people simply disregarded a government that did not have much support. The self-evaluative nature of subjective wellbeing is clearly illustrative here.

Not all personal characteristic variables had an impact on life satisfaction - gender, marriage, occupation, education, and home ownership are examples of this sort. For those that had an impact, apart from income and self-perceived class status, age had the strongest. There are several studies identifying the positive relationship between age and subjective well-being (Campbell and Sawer, 1976; Fernandez and Kulik, 1981; Hong and Giannakopoulos, 1994). If age is regarded to be a proxy for culture, then, the collectivist orientation in traditional Chinese culture should also work well in this case. Perhaps, Hong Kong in the 21 st century is no longer a traditional Chinese society. The alternative explanation may be more convincing, aging as a process helps people to appreciate their constraints; hence, old aged people are more satisfied with their lives. We cannot generalize whether or not materialism, a cultural variable, has any impact on the level of life satisfaction because it was not included in this study. It is important to explore this aspect in any future study. It is worth mentioning that education did not have any impact in this case study; this is contrary to many studies on subjective well-being 
which identify the contrary (Goldlust and Richmond, 1974; Hughes and Thomas, 1998); but in line with the conclusion reached by Inglehart (2000) on the basis of the data from the World Values Survey. All these imply that personal characteristic variables are not necessarily independent by themselves; they are also moderated by the larger society where they are embedded.

On the basis of these findings, subjective well-being should be recognized as an instrument for social-scientific analysis of human welfare. It is sensitive to societal conditions in this single-case study of a rich Chinese society.

\section{Implications for social policy}

Now we turn to the implications of these findings for social policy.

Firstly, perceived government-provided social services, as a proxy for social policy, had an impact on life satisfaction in this case study. This was empirically based, positive evidence for social policy which is usually a big spender of public revenues in a modern society regardless of its budget size. ${ }^{10}$ Despite the weak correlation score, it nevertheless suggests that social policy has a positive impact on life satisfaction. The weak relationship between social policy and life satisfaction may imply that there is more room for social policy to exert its impact on this important end-state measure of subjective well-being. For example, both satisfaction with social and economic conditions, perceptions of severity of social problems, and self-perceived class status had impacts on life satisfaction. This suggests that social policy could contribute indirectly to life satisfaction by improving the quality of its output - good education, less poverty and unemployment, secure community, and also a less socially stratified society. More research needs to be done on how social policy programs can enable people to make choices and invest their efforts for improving their life chances. Depth or focus group interviews should be promising tools to capture the positive role of social policy programs such as educational subsidies, employment assistance, and child support, in this regard.

Secondly, on a comparative perspective, high average national income did not bring forth correspondingly high satisfaction with life to the respondents in Hong Kong. One may wonder whether a policy that predominantly pursues economic growth is really worthy in 
terms of well-being. Government strategies for development should focus more on ways to harmonize economic policy and social policy rather than undertake a single-minded pursuit of the former. In other words, the prevalent emphasis on re-commodifiying labor, such as work for welfare initiatives, is likely counter-productive to subjective well-being. Taken one step further, it seems that social policy's traditional emphasis on the goals of social equality, reciprocity, and the concern for the poor should be beneficial for subjective well-being.

Thirdly and the last, the findings also have implications for income or social redistribution. In the case of Hong Kong, despite its generally high level of average national income - on this basis, the basic needs of its people should be satisfied - but a highly stratified society is likely to reduce the power of income or wealth for life satisfaction. In other words, there is a compelling case to argue that, in such a context, more redistribution is beneficial as it would reduce the income and class gaps. On a different context in the case of more egalitarian affluent countries, whether or not further redistribution beyond the basic needs level is beneficial in terms of subjective wellbeing has to be determined by culture - the underlying meanings of social equality and how they affect the conceptions of social redistribution for well-being. In particular, how people there define basic needs according to the prevalent norms in regards to living standards in society seems to be the key question. This is to say, the diminishing marginal utility for life satisfaction beyond the basic needs level still works, but how 'basic needs' are defined in terms of specific social services and benefits are moderated by culture.

\section{NOTES}

1 World Values Survey 1999-2000, http://www.worldvaluessurvey.org/(downloaded on 8 April 2005).

2 Puerto Rico had a GDP per capital, PPP, of US\$11,500, while that of Mexico was US\$8970 in 2002. Sources: UNDP, World Development Report 2004; World Fact Book, Yahoo: www.education.yahoo.com (downloaded on 2 May 2005.)

${ }^{3}$ For example, the ratio of male and female was 47.2:52.8 in our sample, and 48.4:51.6 in the larger population in 2003; in terms of age, our sample had $19.1 \%$ between 18 and 30, 56.4 between 31 and 59, whilst the respective percentages were 22.4 and 58.8 in the larger population; in terms of education, our sample had $30.6 \%$, $51.9 \%$ and $17.5 \%$ having primary, secondary and tertiary education levels respectively, whilst the corresponding percentages of the larger population were $27.3,51.5$ 
and 21.2. In terms of household income, our sample was similar with that of the larger population $-29.9 \%, 48.0 \%$ and $22.1 \%$ with low, middle and high income; while the respective percentages in the larger population were 30.7, 45.3, and 24.0. The figures of the larger population were obtained from the Government's Census and Statistics Department in early 2004.

${ }^{4}$ Hong Kong Monetary Authority 2003 Annual Report, p. 16.

5 Figures here and below on Hong Kong's general constitutional, economic, and social conditions can be referred to Hong Kong in Brief, in the SAR Hong Kong Government official website: http://www.info.gov.hk/info/hkbrief/eng/index.htm (downloaded 10 May 2005)

${ }^{6}$ For example, the highest gini index reported was Russia, at 48.7, but the second high dropped to 36.1 in the case of Britain; while the lowest gini index was found in a poor East European country, Belarus, at 21.7. See Fahey and Smyth (2004), Table I.

${ }^{7}$ Hong Kong International Airport (HKIA) has been named Best Airport Worldwide by both business and leisure travelers, according to the results of the authoritative AETRA survey. Downloaded on 10 April 2005, HKIA website: www.hongkongairport.com/eng/pr/pr_775b.html.

8 Figures quoted here and after are based on the various reports of the Census and Statistics Department of the SAR Government - Gross Domestic Product and Annual Statistical Report, various years. The SAR Hong Kong Government Printer. US $\$$ figures are converted on US\$1.0 $=\mathrm{HK} \$ 7.8$. Some of figures can also be downloaded from the official website: http://www.info.gov.hk/censtatd/ (downloaded on 10 May 2005).

${ }^{9}$ Unpublished data obtained from the researchers.

${ }^{10}$ For example, Hong Kong spent a little bit more than half of its annual budget on education, housing, health care, and social security in 2002 (Chau and Wong, 2002).

\section{REFERENCES}

Chan, Y.K., C.C. Kwan and D. Shek: 2003, Quality of Life in Hong Kong - The Chinese University of Hong Kong Quality of Life Index (The Chinese University of Hong Kong, Hong Kong).

Chau, R.C.M. and W.K. Yu: 2005, 'Is welfare unAsian?', in A. Walker and C.K. Wong (eds.), East Asian Welfare Regimes in Transition, From Confucianism to Globalisation (Policy Press, Bristol), pp. 21-45.

Chau, K.L. and C.K. Wong: 2002, in S. K. Lau (ed.), The Social Welfare Reform: A Way to reduce Public Burden, The First Tung Chee-wah Administration (The Chinese University Press), pp. 201-236.

Chiu, S. and V. Wong: 2005, 'Hong Kong: familistic to Confucian welfare', in A. Walker and C. K. Wong (eds.), East Asian Welfare Regimes in Transition: From Confucianism to Globalization (Policy Press, Bristol), pp. 73-93.

Cheung, C.K.: 1998, 'Impacts of class on Hong Kong people's well-being', Human Relations 51(1), pp. 89-119.

Christoph, B. and H.-H. Noll: 2003, 'Subjective well-being in the European Union during the 90s', Social Indicators Research 64(3), p. 521.

Campbell, A. and W. Sawer: 1976, 'Life satisfaction in the United States', Social Forces 54(3), pp. 621-631. 
Diener, E., M. Diener and C. Diener: 1995, 'Factors predicting the subjective wellbeing of nations', Journal of Personality and Social Psychology 5, pp. 851-864.

Diener, E. and C. Diener: 1996, 'Most people are happy', Psychological Science 7, pp. 181-185.

Diener, E. and R. Biswas-Diener: 2002, 'Will money increase subjective well-being?', Social Indicators Research 57, pp. 119-169.

Diener, E., R.A. Emmons, R.J. Larsen and S. Griffin: 1985, 'The satisfaction with life scale', Journal of Personality Assessment 49, pp. 71-75.

Diener, E. and R.E. Lucas: 1999, 'Personality and subjective well-being', in D. Kahneman, E. Diener and N. Schwarz (eds.), The Foundations of Hedonic Psychology (Sage, New York).

Diener, E., E.M. Suh, H.L. Smith and L. Shao: 1995, 'National cultural differences in reported subjective well-being: Why do they occur?', Social Indicators Research 34, pp. 7-32.

Diener, E., E.M. Suh and S. Oishi: 1997, 'Recent findings in subjective well-being', Indian Journal of Clinical Psychology March 24, pp. 25-41.

Diener, E. and E.M. Suh: 1997, 'Measuring quality of life: economic, social, and subjective indicators', Social Indicators Research 40, pp. 189-216.

Diener, E., E.M. Suh, R.E. Lucas and H.L. Smith: 1999, 'Subjective well-being Three decades of progress', Psychological Bulletin 125(2), pp. 276-302.

Fahey, T. and E. Smyth: 2004, 'Do subjective indicators measure welfare? Evidence from 33 European societies', European Societies 6(1), pp. 5-27.

Fernandez, R. and J. Kulik: 1981, 'A multilevel model of life satisfaction: effects of individual characteristics and neighborhood composition', American Sociological Review (December), pp. 840-850.

Goldlust, J. and A.H. Richmond: 1974, Multivariate Analysis of Immigrant Adaptation: A Study of Male Householders in Metropolitan Toronto (Ethnic Research Program, York University, Toronto).

Hagerty, M.R.: 1999, 'Unifying livability and comparison theory: cross-national time-series analysis of life satisfaction', Social Indicators Research 47(3), pp. 343357.

Hagerty, M.R. and R. Veenhoven: 2003, 'Wealth and happiness revisited - growing national income does not go with greater happiness', Social Indicators Research 64(1), pp. 1-27.

Holliday, I.: 2000, 'Productivist Welfare Capitalism: Social Policy in East Asia', Political Studies 48, pp. 706-723.

Holliday, I., and P. Wilding (eds.): 2003, Welfare Capitalism in East Asia: Social Policy in the Tiger Economies (Palgrave Macmillan, Hampshire, NY).

Hong, S.M. and E. Giannakopoulos: 1994, 'The relationship of satisfaction with life to personality characteristics', The Journal of Psychology 128(5), pp. 1-8(internet version).

Hughes, M. and M. Thomas: 1998, 'The continuing significance of race revisited: a study of race, class and quality of life in America, 1972 to 1996', American Sociological Review 63(6), pp. 785-795.

Inglehart, R.: 2000, 'Globalization and postmodern values', The Washington Quarterly 23(1), pp. 215-228.

Kasser, T. and R.M. Ryan: 1993, 'A dark side of the American dream: correlates of financial success as a central life aspiration', Journal of Personality and Social Psychology 65, pp. 410-422. 
Maslow, A.H.: 1970, Motivation and Personality (Harper and Row, New York).

McLaughlin, E.: 1993, 'Hong Kong: a residual welfare regime', in A. Cochrane, and J. Clarke (eds.), Comparing Welfare States: Britain in International Context (Sage, London, Newbury Park, New Delhi).

Noll, H.-H.: 2002, 'Towards a European system of social indicators: theoretical Framework and system architecture', Social Indicators Research 58, pp. 47-87.

Oswald, A.J.: 1997, 'Happiness and economic performance', Economic Journal 107, pp. $1815-1831$.

Ouweneel, P.: 2002, 'Social security and well-being of the unemployed in 42 nations', Journal of Happiness 3, pp. 167-192.

Ramesh, M.: 2004, Social Policy in East and Southeast Asia (Routledge Curzon, London, NY).

Richins, M.L. and S. Dawson: 1992, 'A consumer values orientation for materialism and its measurement: scale development and validation', Journal of Consumer Research 19, pp. 303-316.

Schyns, P.: 1998, 'Crossnational differences in happiness: economic and cultural factors explored', Social Indicators Research 43, pp. 3-26.

Sirgy, M.J.: 1998, 'Materialism and quality of life', Social Indicators Research 43, pp. $227-260$.

Walker, A. and C.K. Wong: 1996, 'Rethinking the western construction of the welfare state', International Journal of Health Services 26(1), pp. 67-92.

Walker, A. and C.K. Wong: 2005, East Asian Welfare Regimes in Transition, From Confucianism to Globalisation (Policy Press, Bristol).

Wong, C.K. and K.Y. Wong: 2005, 'Expectations and practice in social citizenship: some insights from an attitude survey in a Chinese city', Social Policy and Administration 39(1), pp. 19-35.

Veenhoven, R.: 1991, 'Is happiness relative?', Social Indicators Research 24, pp. 134.

Veenhoven, R.: 1995, 'The cross-national pattern of happiness: test of predictions implied in three theories of happiness', Social Indicators Research 34, pp. 33-68.

Veenhoven, R.: 2002, 'Why social policy needs subjective indicators', Social Indicators Research 58, pp. 33-45.

Social Work Department

Chack Kie Wong

The Chinese University of Hong Kong

Shatin, NT

Hong Kong,

E-mail: chackkiewong@cuhk.edu.hk 